\title{
Применение магнезиально-силикатного реагента для очистки растворов с высоким уровнем загрязнения
}

\author{
Иванова Т.К., Кременецкая И.П., Дрогобужская С.В. \\ Институт химии и технологии редких элементов и минерального сырья им. И.В. Тананаева ФИЦ КНЦ РАН, \\ Anamumbl,i.kremenetskaia@ksc.ru
}

Аннотация. На примере подотвальных вод Гайского ГОКа показана возможность применения магнезиально-силикатного реагента на основе серпентиновых минералов вместо кальцинированной соды для очистки высококонцентрированных техногенных растворов и раздельного осаждения металлов. Результаты анализа с применением метода масс-спектрометрии показали наличие в исходном растворе широкого спектра элементов, которые сгруппированы исходя из химических и геохимических свойств, а также возможности и целесообразности их утилизации. Степень очистки растворов составила величину более $99 \%$ для железа, алюминия, меди, цинка, мышьяка, кадмия, иттрия и 97-98 \% для кобальта и никеля. Для мышьяка, кадмия, иттрия достигнуты низкие остаточные концентрации на уровне нескольких микрограммов в литре. Остаточная концентрация железа составляет 6.4 мг/л, уровень концентрации остальных металлов в очищенном растворе соответствует 0.1 мг/л. Установлено, что путем изменения дозы реагента, регулируя значение рН, можно добиться раздельного осаждения металлов. Получены осадки, состоящие преимущественно из (1) железа, (2) алюминия и меди и (3) цинка и меди.

Ключевые слова: подотвальные воды, Гайский ГОК, магнезиально-силикатный реагент, серпентиновые минералы, осаждение металлов, очистка растворов, степень очистки.

\section{Magnesia-silicate reagent for purification of solutions with a high level of contamination}

\author{
Ivanova T.K., Kremenetskaya I.P., Drogobuzhskaya S.V. \\ Tananaev Institute of Chemistry - Subdivision of the Federal Research Centre «Kola Science Centre of the \\ Russian Academy of Sciences», Apatity, i.kremenetskaia@ksc.ru
}

\begin{abstract}
The possibility of using magnesia-silicate reagent based on serpentine minerals instead of soda ash for the purification of highly concentrated technogenic solutions and separate metal deposition is shown on the example of the Gaisky GOK basement waters. The results of the analysis using the mass spectrometry method showed the presence in the initial solution of a wide range of elements that are grouped based on the (geo)chemical properties, as well as the possibility and feasibility of their disposal. The degree of purification of the solutions was more than $99 \%$ for iron, aluminum, copper, zinc, arsenic, cadmium, yttrium, and 97-98 \% for cobalt and nickel. Low residual concentrations at the level of several micrograms per liter were obtained for arsenic, cadmium, and yttrium. The residual iron concentration is $6.4 \mathrm{mg} / \mathrm{l}$; the concentration of the remaining metals in the purified solution is $0.1 \mathrm{mg} / \mathrm{l}$. It was found that by changing the dose of the reagent, adjusting the $\mathrm{pH}$ value, it is possible to achieve separate deposition of metals Precipitation obtained, consisting mainly of (1) iron, (2) aluminum and copper, and (3) zinc and copper.

Key words: subsurface water, Gaisky GOK, magnesia-silicate reagent, serpentine minerals, metal deposition, solution cleaning, degree of purification.

\section{Введение}

Примером глубокой трансформации природной среды с образованием техногенных комплексов является территория размещения объектов ПАО «Гайский ГОК» - основной сырьевой базы Уральской горно-металлургической компании. На Гайском месторождении, где переход от рудных залежей к пустой породе происходит постепенно, накопление сульфидов в отвалах является неизбежным. Некондиционные руды с низким содержанием $\mathrm{Cu}$ и $\mathrm{Zn}$ направлялись в отдельные отвалы, под которыми воды техногенного горизонта являются наиболее кислыми (pH 2) и чрезвычайно агрессивными (Захарова, Погосян, 2011). В работе, выполненной при участии специалистов компании «УГМК-холдинг», отмечается, что запасы гидроминерального сырья, образованного в резуль-
\end{abstract}


тате деятельности горно-обогатительных предприятий, сопоставимы по отдельным элементам с известными месторождениями твердых полезных ископаемых (Медяник, 2012).

Мероприятия, направленные на аккумуляцию кислых минерализованных вод в прудахнакопителях, способствовали локализации загрязнения (Захарова, Погосян, 2011), однако не решили, да и не могли решить проблемы загрязнения объектов гидросферы (Гаев, Погосян, 2011). В последней публикации отмечается, что в целом по Оренбургской области, где расположен Гайский ГОК, хорошее качество установлено только для подземных вод на площадях с лесонасаждениями и зонами рекреации.

В подотвальных водах Гайского ГОКа содержание алюминия и железа составляет величину порядка 2 г/л, меди и цинка -0.5 г/л. Техногенные воды являются не только высококонцентрированными по некоторым элементам, но и содержат как высокотоксичные, так и весьма ценные компоненты. Ранее была разработана технология раздельного осаждения металлов с применением кальцинированной соды. Представляет интерес замена кальцинированной соды на другие, менее дорогостоящие щелочные реагенты. Привлекательным вариантом является использование термоактивированных серпентиновых минералов (Кременецкая и др., 2012). Данные продукты представляют собой комплексный магнезиально-силикатный реагент, который обладает кислотонейтрализующей способностью благодаря наличию активного оксида магния. В Оренбургской области, где расположен Гайский ГОК, находится также предприятие по добыче магнезита, в месторождении которого сосредоточены в виде вскрышных пород неограниченные запасы серпентинового сырья. В настоящей работе представлены результаты оценки возможности применения термоактивированных серпентиновых минералов для очистки подотвальных вод Гайского ГОКа.

\section{Химический состав подотвальных вод Гайского ГОКа}

Проба подотвальных вод Гайского ГОКа представляет собой раствор цвета ржавчины; значение $\mathrm{pH}$, измеренное после отделения из раствора осадка, составляет величину 2.3. В составе анионов преобладают сульфаты (концентрация $\mathrm{SO}_{4}^{2-}-23.42$ г/л), в растворе присутствуют также хлориды и нитраты с концентрацией $\mathrm{Cl}^{-}-0.18$ и $\mathrm{NO}_{3}^{-}-0.20$ г/л.

Результаты анализа с применением метода масс-спектрометрии (масс-спектрометр с индукционно связанной плазмой ELAN-9000 DRC-e (Perkin Elmer, CША)) показали наличие в растворе широкого спектра элементов. Обнаруженные элементы сгруппированы исходя из (гео)химических свойств, а также возможности и целесообразности их утилизации (рис. 1). Следует отметить, что железо и алюминий, являющиеся петрогенными элементами, отнесены к группе металлов в соответствии с техногенным происхождением, а также необходимостью извлечения из раствора и дальнейшей утилизации вследствие экстремально высокой концентрации данных компонентов.

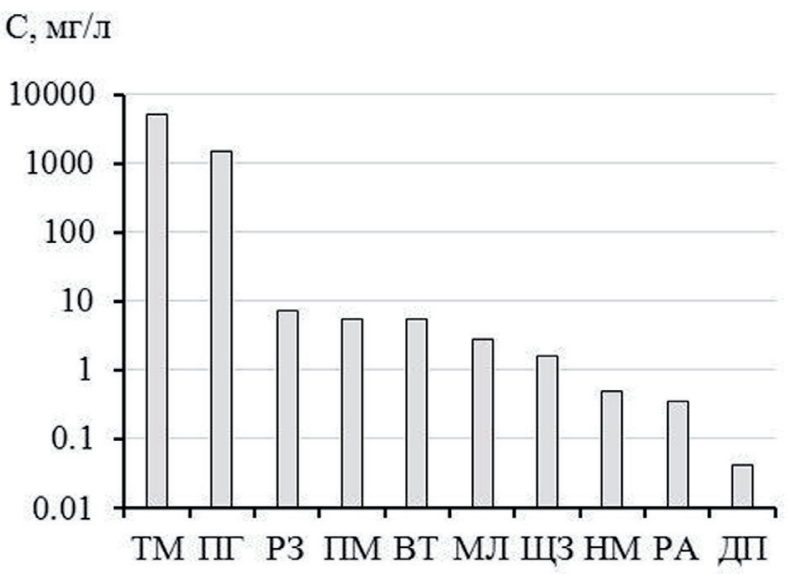

$\begin{array}{ll}\text { TМ } & \text { Металлы } \\ \text { ПГ } & \text { Петрогенные элементы } \\ \text { Р3 } & \text { Редкоземельные металлы } \\ \text { ПМ } & \text { Переходные металлы } \\ \text { ВТ } & \text { Высокотоксичные элементы, яды } \\ \text { МЛ } & \text { Металлоиды } \\ \text { Щ3 } & \text { Щелочноземельные металлы } \\ \text { НМ } & \text { Неметаллы } \\ \text { РА } & \text { Радиоактивные элементы } \\ \text { ДП } & \text { Драгоценные и платиновые металлы }\end{array}$

Рис. 1. Содержание групп элементов в подотвальных водах Гайского ГОКа.

Fig. 1. The content of groups of elements in the Gaisky GOK basement waters. 
В количестве нескольких граммов
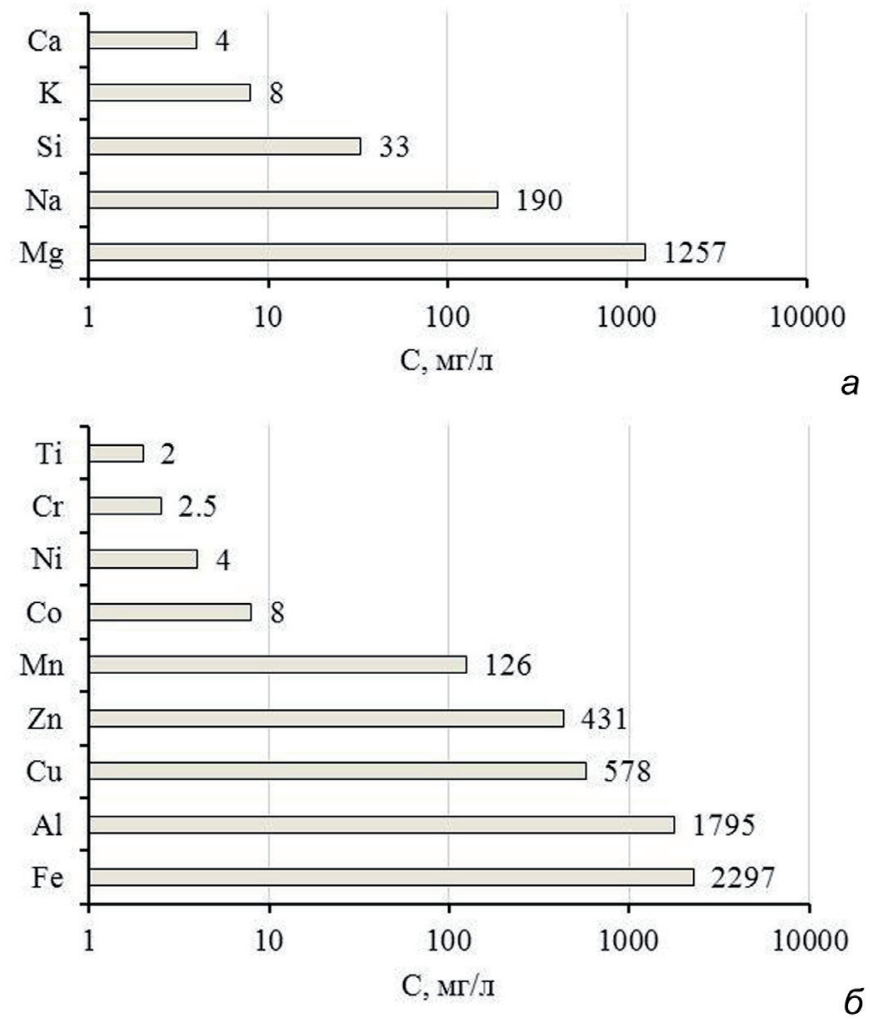

Рис. 2. Содержание элементов петрогенного происхождения (a) и металлов (б) в пробе подотвальных вод Гайского ГОКа.

Fig. 2. The content of elements of petrogenic origin ( $a$ ) and metals $(b)$ in the sample of the Gaisky GOK basement waters. на литр в растворе присутствуют металлы и петрогенные элементы. Концентрации петрогенных элементов и металлов представлены на рисунке 2. Среди петрогенных элементов наиболее высокие концентрации наблюдаются для магния, в заметных количествах обнаружены натрий и кремний, а кальций и калий практически отсутствуют (рис. 2 а). Что касается металлов, то в этой группе в концентрациях несколько граммов на литр содержатся железо и алюминий, примерно в одинаковом количестве порядка 0.5 г/л - целевые металлы деятельности Гайского ГОКа медь и цинк (рис. 2 б). Концентрации никеля, кобальта, хрома и титана изменяются в пределах 2-8 мг/л. Данные концентрации незначительны по сравнению с медью и цинком, однако являются очень высокими с точки зрения нормативов загрязнения природной среды.

В группе редкоземельных элементов наиболее высокая концентрация отмечена для иттрия (3 мг/л), в три раза меньше церия и неодима (рис. 3). Содержание остальных элементов данной группы на один-два порядка меньше.

Исходя их представленных данных установлен перечень компонентов, концентрации которых определяли в экспериментах по очистке пробы подотвальных вод Гайского ГОКа магнезиальносиликатным реагентом. В качестве контролируемых параметров использовали концентрации железа, алюминия, меди, цинка, кобальта, никеля. Эффективность осаждения редкоземельных элементов оценивали по концентрации иттрия. Определяли также содержание мышьяка и кадмия, которые относятся к группе высокотоксичных элементов (ядов). Поведение компонентов, концентрации которых в исходном растворе менее 1 мг/л, не исследовали.

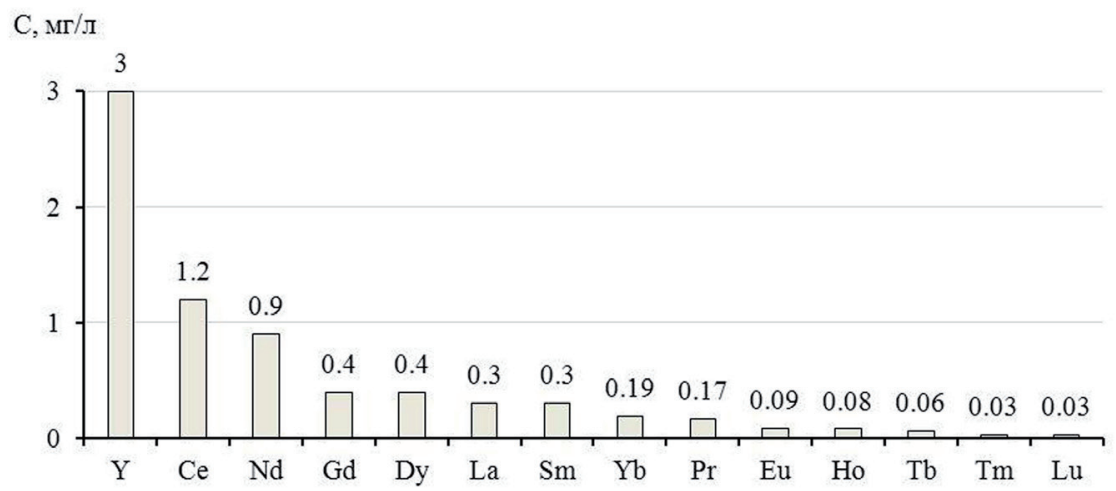

Рис. 3. Содержание редкоземельных элементов в пробе подотвальных вод Гайского ГОКа.

Fig. 3. The content of rare earth elements in the sample of the Gaisky GOK basement waters. 


\section{Результаты экспериментов по очистке пробы подотвальных вод}

Эксперименты по очистке пробы подотвальных вод Гайского ГОКа выполнены в два этапа. Параметры проведения экспериментов, такие как соотношение реагента и раствора, способ внесения реагента, продолжительность взаимодействия и рН полученных суспензий, представлены в таблице. На первом этапе получены данные, на основании которых можно судить о максимально возможной эффективности очистки данного раствора магнезиально-силикатным реагентом (эксперимент I). Целью второго этапа (эксперимент II) является создание условий для раздельного осаждения компонентов раствора.

Таблица. Условия и результаты эксперимента по очистке пробы подотвальных вод Гайского ГОКа магнезиально-силикатным реагентом.

Table. The conditions and results of the experiment on the purification of a sample of the Gaisky GOK basement waters with a magnesia-silicate reagent.

\begin{tabular}{|c|c|c|c|c|c|}
\hline \multirow{3}{*}{$\begin{array}{c}\text { Параметры } \\
\text { эксперимента }\end{array}$} & \multirow{3}{*}{$\begin{array}{l}\text { Исходный } \\
\text { раствор }\end{array}$} & \multicolumn{4}{|c|}{ Растворы после очистки } \\
\hline & & \multirow[b]{2}{*}{ Эксперимент I } & \multicolumn{3}{|c|}{ Эксперимент II } \\
\hline & & & II-a & II-b & II-c \\
\hline $\mathrm{pH}$ & 2.32 & 8.59 & 3.9 & 6.8 & 8.8 \\
\hline \multicolumn{2}{|c|}{ Способ внесения реагента } & $\begin{array}{l}\text { Постепенно в течение } 1 \text {-го } \\
\text { часа порциями } 5 \Gamma+4 \times 1 \text { г }\end{array}$ & \multicolumn{3}{|c|}{$\begin{array}{l}\text { Последовательно от II-а к II-c, раствор } \\
\text { отделяли от осадка и вновь добавляли } \\
\text { реагент }\end{array}$} \\
\hline \multicolumn{2}{|c|}{ Отношение Т/Ж, г/мл } & $10 / 200$ & $10 / 400$ & $10 / 340$ & $5 / 270$ \\
\hline \multicolumn{2}{|c|}{$\begin{array}{l}\text { Продолжительность } \\
\text { взаимодействия, ч }\end{array}$} & 24 & 2 & 2 & 1 \\
\hline
\end{tabular}
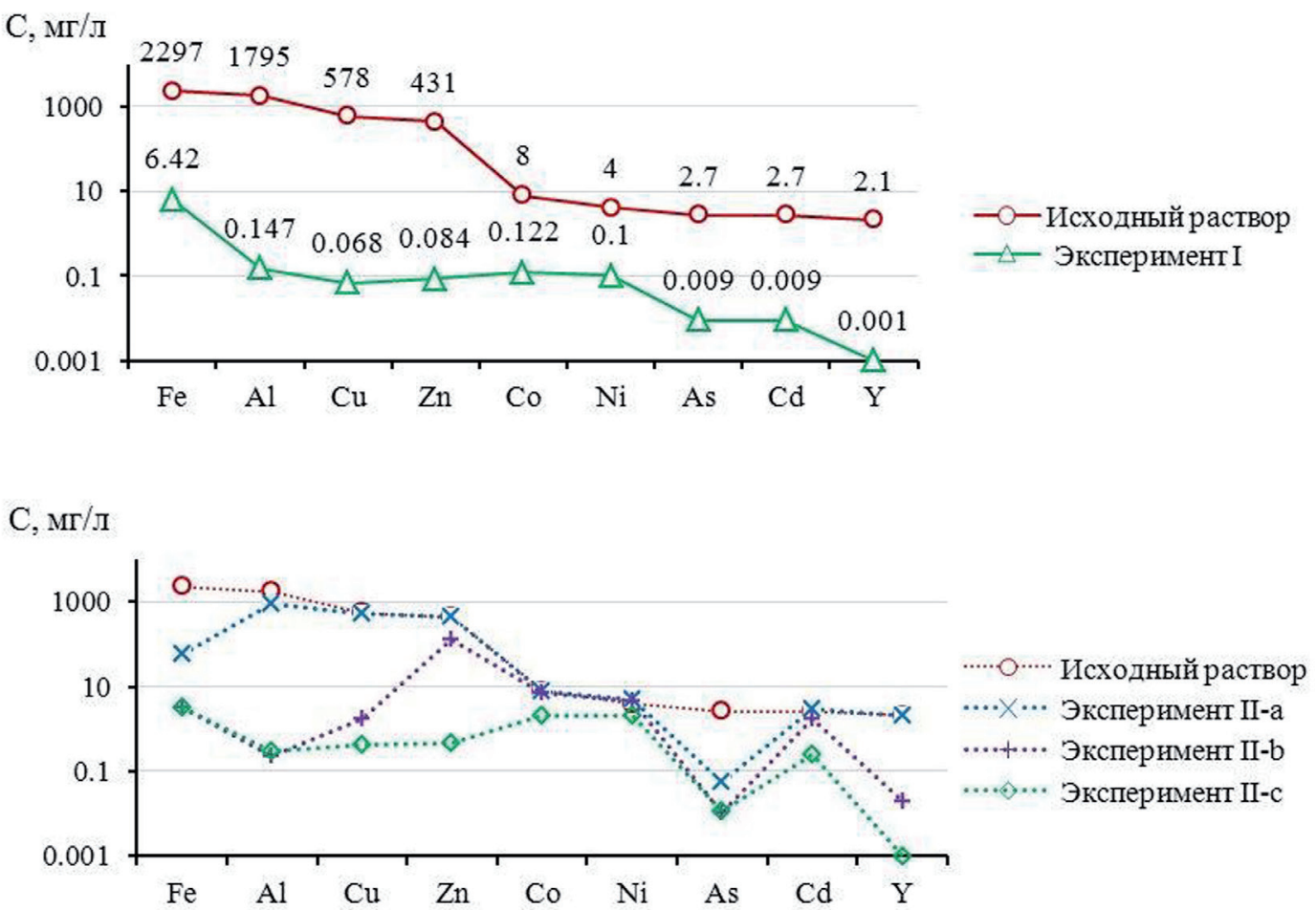

Рис. 4. Концентрации компонентов в растворе до и после очистки при проведении эксперимента I (a) и эксперимента II (б), условия экспериментов представлены в таблице.

Fig. 4. The concentration of components in the solution before and after purification in experiment I (a) and experiment II (b), the experimental conditions are presented in Table. 
На рисунке 4 представлены мультиэлементные диаграммы массовых концентраций компонентов в исходном растворе и в растворах после очистки. В эксперименте I степень очистки растворов более 99 \% для железа, алюминия, меди, цинка, мышьяка, кадмия, иттрия и 97-98 \% для кобальта и никеля. Низкие остаточные концентрации на уровне нескольких микрограммов в литре получены для мышьяка, кадмия, иттрия. Остаточная концентрация железа составляет величину 6.4 мг/л, уровень концентрации остальных металлов в очищенном растворе соответствует 0.1 мг/л (рис. 4 а).

Эксперимент II показал, что путем изменения дозы реагента, регулируя значение $\mathrm{pH}$, можно добиться раздельного осаждения металлов. В эксперименте II-а получен осадок, состоящий преимущественно из железа. В эксперименте II-b осаждаются алюминий и медь, и на последней стадии - цинк и медь (рис. 4 б).

Таким образом, на основании полученных результатов можно предложить заменить в технологии очистки подотвальных вод Гайского ГОКа дорогостоящую кальцинированную соду на магнезиально-силикатный реагент на основе серпентиновых минералов.

Работа выполнена при поддержке торгово-промышленной палаты г. Новотроицк, Оренбургская обл.

\section{Литература}

1. Гаев А.Я., Погосян Ю.М. О состоянии природных вод Оренбуржья // Тезисы докладов II Международной конференции «Окружающая среда и менеджмент природных ресурсов», Тюмень, 15-17 ноября 2011 г. (под ред. А.В. Соромотина, А.В. Толстикова). Тюмень. Изд-во: Тюменского государственного университета. 2011. С. 154-159.

2. Захарова В.Я., Сквалецкий Е.Н. Геоэкологические прогнозы условий разработки Южно-уральских медноколчеданных месторождений // Проблемы региональной экологии. 2011. № 5. С. 34-37.

3. Кременецкая И.П., Лащук В.В., Волочковская Е.Ю., Дрогобужская С.В., Морозова Т.А. Применение магнезиально-силикатного реагента для очистки от тяжелых металлов природно-антропогенных водных источников, расположенных в зоне воздействия ОАО «Кольская ГМК» (площадка Мончегорск) // Цветные металлы. 2012. № 7. С. 35-40.

4. Медяник Н.Л. Теоретическое обоснование и разработка ресурсовоспроизводящих технологий комплексной переработки техногенных вод медно-цинковых горных предприятий. Автореф. дис. ... докт. технич. наук. М. 2012. 41 с. 